Published in final edited form as:

Ann Surg Oncol. 2018 June ; 25(6): 1502-1511. doi:10.1245/s10434-018-6359-z.

\title{
Use of Breast Imaging After Treatment for Locoregional Breast Cancer (AFT-01)
}

\author{
Taiwo Adesoye, MD MPH${ }^{1}$, Jessica R. Schumacher, PhD $^{1}$, Heather B. Neuman, MD MS ${ }^{1,2}$, \\ Stephen Edge, MD $^{3}$, Daniel McKellar, $\mathbf{M D}^{4}$, David P. Winchester, $\mathbf{M D}^{4}$, Amanda B. \\ Francescatti, MS $^{4}$, Caprice C. Greenberg, MD MPH ${ }^{1,2}$, Alliance ACS-CRP CCDR Breast \\ Cancer Surveillance Working Group \\ ${ }^{1}$ Wisconsin Surgical Outcomes Research Program, Department of Surgery, University of \\ Wisconsin-Madison School of Medicine and Public Health, Madison, WI \\ ${ }^{2}$ University of Wisconsin Carbone Cancer Center, University of Wisconsin School of Medicine and \\ Public Health, Madison, WI \\ ${ }^{3}$ Roswell Park Cancer Institute, Buffalo, NY \\ ${ }^{4}$ American College of Surgeons, Commission on Cancer, Chicago, IL
}

\section{Abstract}

Background.-Annual mammography is recommended after breast cancer treatment. However, studies suggest its under-utilization for Medicare patients. Utilization in the broader population is unknown, as is the role of breast magnetic resonance imaging (MRI). Understanding factors associated with imaging use is critical to improvement of adherence to recommendations.

Methods.-A random sample of 9835 eligible patients receiving surgery for stages 2 and 3 breast cancer from 2006 to 2007 was selected from the National Cancer Database for primary data collection. Imaging and recurrence data were abstracted from patients 90 days after surgery to 5 years after diagnosis. Factors associated with lack of imaging were assessed using multivariable repeated measures logistic regression with generalized estimating equations. Patients were censored for death, bilateral mastectomy, new cancer, and recurrence.

Results: Of 9835 patients, $9622,8702,8021$, and 7457 patients were eligible for imaging at surveillance years 1 through 4 respectively. Annual receipt of breast imaging declined from year 1 (69.5\%) to year $4(61.0 \%)$, and breast MRI rates decreased from 12.5 to 5.8\%. Lack of imaging was associated with age 80 years or older and age younger than 50 years, black race, public or no insurance versus private insurance, greater comorbidity, larger node-positive hormone receptornegative tumor, excision alone or mastectomy, and no chemotherapy ( $\mathrm{p}<0.005)$. Receipt of breast

Correspondence: Caprice C. Greenberg, M.D., M.P.H. Professor Department of Surgery, University of Wisconsin-Madison School of Medicine and Public Health, 600 Highland Avenue, Madison, WI 53792, Phone: 608-266-6400, Greenberg@ surgery.wisc.edu.

Publisher's Disclaimer: DISCLAIMER The data used in the study are derived from a deidentified National Cancer Database file. The American College of Surgeons and the Commission on Cancer have not verified and are not responsible for the analytic or statistical methods used or the conclusions drawn from these data by the investigator. Furthermore, the contents of this publication are solely the responsibility of the authors and do not necessarily represent the official view of PCORI or NIH. All statements in this publication, including its findings, are solely those of the authors and do not necessarily represent the views of NIH or PCORI, its Board of Governors or Methodology Committee. 
MRI was associated with age younger than 50 years, white race, higher education, private insurance, mastectomy, chemotherapy, care at a teaching/research facility, and MRI 12 months before diagnosis $(\mathrm{p}<0.05)$.

Conclusion: Under-utilization of mammography after breast cancer treatment is associated with sociodemographic and clinical factors, not institutional characteristics. Effective interventions are needed to increase surveillance mammography for at-risk populations

\section{INTRODUCTION}

Approximately 3 million women living in the United States have a history of breast cancer. ${ }^{1}$ The American Society of Clinical Oncology (ASCO) and the National Comprehensive Cancer Network (NCCN) guidelines recommend an annual mammography, starting 6 to 12 months after radiation therapy (RT) or 12 months after the last screening mammogram of the contralateral breast. ${ }^{2,3}$ The goal of annual mammography in this setting is early detection of in-breast recurrences or new primary breast tumors.

Breast cancer survivors, particularly women with breast cancer diagnosed at stage 2 or 3 , have an increased risk of future breast cancer events despite significant advances in locoregional and systemic therapy. ${ }^{4-7}$ Several observational studies describe variation in the receipt of surveillance mammography, with under-utilization related to older age, racial/ ethnic minorities, higher disease stage, and receipt of breast-conserving surgery without radiation. ${ }^{8-12}$ However, these studies are mainly from a single institution or restricted to an older Medicare population, thereby limiting generalizability. This study aimed to examine patterns of utilization and factors associated with use of screening mammography and breast magnetic resonance imaging (MRI) after treatment for stage 2 or 3 breast cancer in a diverse cohort of patients drawn from a large number of hospitals across the United States. Although current guidelines do not recommend breast MRI for surveillance, we included MRI use as an exploratory analysis given its increasing utilization. We hypothesized that post-treatment mammography will be under-utilized, with underuse associated with patient-level socioeconomic and clinical factors, but not institutional factors.

\section{METHODS}

\section{Data Source}

As part of a special study, a stage-stratified random sample of 10 eligible patients ( 7 with stage 2 and 3 with stage 3 breast cancer) was selected from each of 1231 facilities accredited by the American College of Surgeons' Commission on Cancer (CoC) in 2006 and 2007. Using an electronic data collection platform and a standardized abstraction form, we extracted data on breast imaging and recurrence from the medical records of facilities involved in the active treatment or surveillance of each patient. Data were collected on 11,366 patients from 1217 hospitals, for a 99\% participation rate. Imaging and recurrence information was abstracted from patients 90 days after surgery to 5 years after diagnosis or until distant recurrence or death, and information was requested from each hospital where care was delivered. 
The National Cancer Data Base (NCDB) is a joint program of the $\mathrm{CoC}$ and the American Cancer Society that records information on $70 \%$ of all newly diagnosed malignances in the United States from approximately 1400 accredited facilities. ${ }^{13}$ Data are abstracted from patient charts by trained registrars using the Facility Oncology Registry Data Standards manual ${ }^{14}$ and subjected to rigorous integrity checks. Once patients have cancer diagnosed, are treated at a $\mathrm{CoC}$ accredited facility, or both, accreditation standards require registrars to follow $90 \%$ of these patients for survival regardless of where they receive care. ${ }^{13}$ The NCDB includes patient and tumor characteristics, detailed staging information, first-course treatments, and mortality, with additional information on treatment facilities.

\section{Patient Selection}

The study included female patients age 18 years and older with a histologically confirmed American Joint Committee on Cancer (AJCC) stage 2 or 3 breast cancer diagnosis who underwent surgery with curative intent in 2006 or 2007. Patients were excluded if their diagnosis date was unknown $(\mathrm{n}=16)$. We also excluded patients with significant cancer and non-cancer events within 10 months after diagnosis (death: $\mathrm{n}=157$, local or distant recurrence: $\mathrm{n}=197$, new cancer: $\mathrm{n}=52$, receipt of bilateral mastectomy: $\mathrm{n}=1109$ ) (Fig. 1). These exclusions resulted in a final cohort of patients who had completed definitive therapy for the index cancer, were disease free, and were eligible for surveillance breast imaging 10 months after diagnosis $(n=9835)$.

\section{Breast Imaging: Definition and Timeframe}

Date, type, indication, and results of breast imaging studies performed were recorded. Patients were categorized as receiving surveillance breast imaging during each of 4 followup years (year 1: 10-23 months after diagnosis, year 2: 24-35 months after diagnosis, year 3: 36- 47 months after diagnosis, and year 4: 48-59 months after diagnosis) if they received at least one screening or diagnostic mammogram or breast MRI during each period. The first follow-up year started 10 months after diagnosis to ensure completion of RT, exclusion of imaging related to the primary tumor or ongoing primary therapy, and capture of the first surveillance breast imaging recommended 6 to 12 months after surgery.

\section{Cancer Registry Data}

The special study data were supplemented with data elements from the existing NCDB cancer registry. The sociodemographic factors included age, race, insurance status, and patient zip code-level education and comorbidity (Charlson Deyo comorbidity index, categorized as 0,1 , and 2 or more). Tumor-related factors included AJCC pathologic stage, tumor size, nodal status, abstracted HER2Neu status, and estrogen receptor (ER) and progesterone receptor (PR) status. Treatment characteristics included receipt of adjuvant radiotherapy and/or chemotherapy, surgery type, and characteristics of the diagnosis/ treatment facility. (Figure 2).

\section{Statistical Analysis}

In each surveillance year, patients were censored if they no longer had at-risk breast tissue due to bilateral mastectomy or if they had a new primary non-breast cancer because 
surveillance strategies would change for these patients. Patients also were censored the year after a new breast event (locoregional recurrence or new breast primary tumor) or a distant recurrence because the screening breast imaging would no longer be recommended for them.

Of 9835 patients included in our study, 9622 eligible patients were included in surveillance year 1, 8702 in year 2, 8021 in year 3, and 7457 in year 4. We examined the relationship between sociodemographic, tumor, and treatment factors and receipt of breast imaging by eligible patients in the first year of surveillance $(n=9622)$ using the $\chi^{2}$ test. Similarly, we examined this relationship for annual receipt of imaging during all 4 years of the follow-up period for patients not censored in any of the follow-up years $(n=7457)$. Multivariable repeated-measures logistic regression with generalized estimating equations (GEE) was used to ascertain factors associated with receipt of breast imaging. This approach allows for comparison of findings with prior research using administrative claims and integrates available longitudinal information on imaging use for each patient. ${ }^{8}$ Analyses were conducted using SAS v9.4 (SAS Institute Inc, Cary, NC, USA) and Stata v13 (Stata Corporation, College Station, TX, USA).

\section{RESULTS}

\section{Patient characteristics}

Among the patients eligible for surveillance during the first follow-up year, the mean age at diagnosis was 60 years (range 22-101 years), and the majority of the patients were Caucasian $(83.2 \%)$. More than half of the cohort $(52.3 \%)$ was privately insured, and $60.1 \%$ had no comorbidities. A majority of the patients had hormone (ER and/or PR)-positive (75.4\%) and HER2neu-negative (73.7\%) disease. A majority (72.2\%) also had a diagnosis of stage 2 disease, and $27.8 \%$ had stage 3 disease. Breast conserving surgery was performed for $48.9 \%$ of these patients, and $89.8 \%$ received radiation therapy. Chemotherapy was administered to $71.8 \%$ of the cohort, and $52.7 \%$ received care at a comprehensive community cancer center (Table 1).

\section{Receipt of Surveillance Breast Imaging}

Annual surveillance breast imaging declined from follow-up year 1 to follow-up year 4. Of 9622 patients eligible for imaging in the first surveillance year, $69.5 \%$ received breast imaging. In the final year of the follow-up period (surveillance year 4), 7457 patients were eligible for breast imaging, and $61 \%$ received it. Of the eligible patients not censored in any follow-up year $(\mathrm{n}=7457), 42.3 \%$ received annual imaging during all 4 follow-up years. The annual receipt of surveillance breast MRI ranged from $12.5 \%$ in year 1 to $5.8 \%$ in year 4 . Similar variables were associated with under-utilization of breast imaging during the first year and across all 4 years of the follow-up period in the univariate analyses (Table 1).

\section{Multivariable logistic regression with generalized estimating equations (GEEs)}

Lack of breast imaging was associated with age of 80 years or older and age younger than 50 years, black versus white race, lower education, lack of insurance or receipt of public insurance (Medicaid/Medicare) versus private insurance, having one or more comorbidities, larger tumor size, positive nodes, and negative hormone receptor status $(\mathrm{p}<0.05)$ (Table 2). 
Patients who received chemotherapy and breast-conserving surgery with RT were more likely to receive surveillance breast imaging $(\mathrm{p}<0.0001)$. Patients who received a breast MRI 12 months before diagnosis also were significantly more likely to receive breast imaging $(\mathrm{p}<0.0001)$ (Table 2). Receipt of imaging did not differ significantly by facility type or HER2neu status.

In the model predicting receipt of MRI compared with mammography alone, age younger than 50 years, white versus black race, higher education, private insurance, no comorbidities, receipt of mastectomy and chemotherapy, and care at a teaching/research facility versus community practice were associated with receipt of MRI imaging ( $p<0.05)$. Receipt of MRI in the 12 months preceding diagnosis was strongly associated with receipt of MRI during the follow-up period $(\mathrm{p}<0.00001)$.

\section{DISCUSSION}

This is the first longitudinal study of breast imaging after locoregional treatment of breast cancer using a nationally representative cohort of breast cancer survivors. For patients with stage 2 or 3 breast cancer, the study demonstrated under-utilization of breast imaging after curative treatment. Nonclinical factors such as age, black race, and lack of private insurance as well as clinical factors related to tumor and treatment characteristics were associated with a decreased likelihood of imaging. These results have clinical significance because receipt of surveillance mammography has been shown to decrease breast cancer-specific and all-cause mortality among breast cancer survivors, and lower rates of surveillance mammography may result in increased rates of advanced disease at presentation of recurrence. ${ }^{15-18}$

Neuman et al. ${ }^{19}$ examined the method for detecting locoregional breast and lymph node events among patients who underwent breast-conserving surgery for stage 2 or 3 breast cancer using the same data. A locoregional breast event was detected in $5.5 \%$ of the patients $(n=265)$ at a median 2.9 years after diagnosis, and $48 \%$ of these events were detected on routine imaging compared with $10 \%$ detected by physicians and $29 \%$ detected by the patient. These findings highlight the important role of breast imaging in detecting locoregional recurrence, emphasizing the importance of increasing its use.

Our findings are consistent with those from studies documenting under-utilization of surveillance breast imaging in the elderly Medicare population using administrative claims. $8-10,20,21$ In our study, the annual receipt of breast imaging declined during 4 years of follow-up evaluation, from 69.5 to 61 , and $42.3 \%$ of the patients received consecutive annual imaging during the entire follow-up period. Similarly, prior studies confirm that the use of surveillance mammography peaks 12 to 36 months after diagnosis. ${ }^{21,22}$ Lower utilization than previously described may reflect a more inclusive cohort. ${ }^{8,23-25}$ Furthermore, surveillance of the contralateral breast may have lower priority for patients who have undergone mastectomy, especially stage 2 or 3 patients with a higher risk of distant recurrence because they are overrepresented in this study. Approximately $30 \%$ of the patients did not receive surveillance imaging in the first year of surveillance. This represents a missed opportunity to engage patients formally in a structured surveillance program as they transition from active treatment. Only $42.3 \%$ of eligible patients received annual 
imaging during the follow-up period, emphasizing the importance of ensuring that patients initiate and continue to receive recommended care long term.

Patients younger than 50 years and those older than 80 years were the least likely to receive surveillance imaging. In a survey assessing the relationship between fear of recurrence and health behaviors among younger breast cancer survivors, higher fear of recurrence was associated with excessive use of self-surveillance techniques (breast self-exams), but with reduced use of recommended surveillance including mammograms. ${ }^{26}$ We hypothesize that other causes of this finding could include competing priorities due to work schedules and family pressures. Prior studies show that younger women are at higher risk of recurrence or a second breast cancer event. ${ }^{27-29}$ However, contemporary studies demonstrate that the prognostic impact of age may be dependent on molecular subtype, indicating a more aggressive tumor biology in younger women. ${ }^{30}$ Although they would most likely benefit from early detection of an event, we show that they are less likely to receive it.

Studies of elderly Medicare patients demonstrate that older women were less likely to receive imaging, ${ }^{8,9,11,20}$ as we also demonstrated with the older group in our study. This may relate to the perception that post-treatment surveillance is unlikely to provide significant improvement in survival for elderly patients with limited expected survival due to comorbidities or that patients desire to avoid detection of clinically insignificant cancer. ${ }^{8,20}$

Similar to prior studies, we found that women with a greater number of comorbid conditions were less likely to receive surveillance breast imaging. ${ }^{27,31,32}$ Patients with comorbid conditions and limited life expectancy may forgo locoregional surveillance, reflecting competing medical priorities and the challenge that providers and patients face coordinating care for chronic conditions while adhering to surveillance guidelines. As breast cancer care improves, receipt of appropriate cancer survivorship care in the context of other illnesses will be a priority, and providers should work with patients to determine care goals that optimize quality of life.

Patients with advanced locoregional disease are at higher risk for recurrence and likely would benefit from routine surveillance. However, in our study, the patients with larger tumors, positive nodes, and negative hormone receptor status were less likely to be imaged after adjustment for treatment received. A Surveillance, Epidemiology, and End Results (SEER)-Medicare study of surveillance mammography for early-stage breast cancer survivors found that larger tumor size was associated with lower rates of imaging ${ }^{8}$ and suggests that this may represent physician selection due to favorable prognosis. Conversely, patients with ER/PR-positive tumors are more likely to receive breast imaging, and this may be a function of receiving hormonal therapy, which requires regular interaction with providers, possibly facilitating better access to consistent survivorship care. However, these potential explanations must be explored further.

In a patient population with variable access to care, we demonstrated that insurance type independently predicts under-utilization of post-treatment breast imaging. Women with public or no insurance are less likely than women with private insurance to receive imaging. Many studies examining surveillance mammography use among breast cancer survivors 
were unable to examine the role of insurance because the data were unavailable or the entire cohort was insured..$^{8,21,25,33}$ Facility type at the time of diagnosis and first course treatment was not associated with the likelihood of receiving imaging, suggesting that unlike institutional variation identified in surgical treatment of breast cancer, surveillance practice does not vary at the institutional level in an adjusted analysis. ${ }^{34}$

Guidelines do not recommend surveillance breast MRI for women with a personal history of breast cancer. ${ }^{3}$ However, MRI may be indicated if the woman's lifetime risk is $20 \%$ or greater. ${ }^{35}$ Although the context of MRI use was unknown in our study, 5.8 to $12.5 \%$ of our cohort received at least one MRI during the follow-up period, which is higher than previously reported. ${ }^{20,36}$ The increasing availability of advanced imaging for patients with cancer diagnosed in recent years may contribute to this increased utilization. Use of MRI was associated with younger age, receipt of mastectomy, and care at a teaching/ research facility. Breast MRI may better distinguish normal dense breast tissue typically found in younger women from breast cancer than mammography and may explain its use in this cohort. ${ }^{37-39}$ Family history or other unreported risk factors may place their risk above $20 \%$. Furthermore, studies suggest that MRI may be superior to traditional imaging in detecting recurrence within scar tissue. ${ }^{37,38}$ However, high cost, false-negative results with subsequent additional testing or procedures, and unknown survival benefit limit the indication for postoperative MRI surveillance. ${ }^{40-43}$

Our study had several limitations. Given that this was a retrospective study based on chart abstraction and registry data, ensuring accurate abstraction of relevant data elements was challenging. To address this, detailed abstraction instructions were provided to registrars, weekly webinars were instituted to ensure consistent abstraction, abstraction instructions were piloted in 18 facilities to ensure feasibility, and a planned reliability study was conducted for a random 5\% sample of patients, ensuring high-quality data abstraction. Registrars reported high confidence in the data quality. Our approach represents a major improvement in data quality, which is a significant limitation of prior surveillance studies using administrative databases. We were unable to abstract important determinants of MRI use, including BRCA status, family history of breast cancer, and breast density. Use of MRI in the prior year was used as a surrogate measure to represent some of these factors.

Despite the known advantages of post-treatment surveillance, we demonstrated underutilization of guideline-concordant breast imaging in socioeconomically disadvantaged groups and patients at highest risk for recurrence. It is critical for providers and health systems to recognize barriers to receipt of recommended breast screening imaging, especially immediately after active treatment of breast cancer.

\section{ACKNOWLEDGMENTS}

The research reported in this article was funded through a Patient-Centered Outcomes Research Institute (PCORI) Award (CE-1304-6543) and National Cancer Institute at the National Institutes of Health (NIH) grant number U10CA180821 to the Alliance for Clinical Trials in Oncology. Further funding came from the Building Interdisciplinary Research Careers in Women's Health Scholar Program and University of Wisconsin Carbone Comprehensive Cancer Center Academic Oncologist Training Program (Neuman, NIH K12 HD055894, 5K12CA087718), and the National Cancer Institute funded Surgical Oncology Research Training Program (Adesoye, T32 CA090217). 


\section{REFERENCES}

1. Surveillance epidemiology and end results (SEER). SEER stat fact sheets: breast cancer, 2013 https://seer.cancer.gov/statfacts/html/breast.html.

2. Khatcheressian JL, Hurley P, Bantug E, et al. Breast cancer follow-up and management after primary treatment. American society of clinical oncology clinical practice guideline update. J Clin Oncol. 2013;31:961-5. [PubMed: 23129741]

3. Oncology NCPGi. Breast cancer screening and diagnosis, Version 1.2016. 2016 Retrieved 2 Feb 2017 at https://www.nccn.org/professionals/physician_gls/pdf/breast.pdf.

4. Saphner T, Tormey DC, Gray R. Annual hazard rates of recurrence for breast cancer after primary therapy. J Clin Oncol. 1996;14:2738-46. [PubMed: 8874335]

5. Colleoni M, Sun Z, Price KN, et al. Annual hazard rates of recurrence for breast cancer during 24 years of follow-up: results from the International breast cancer study group trials I to V. J Clin Oncol. 2016;34:927-35. [PubMed: 26786933]

6. Cuzick J, Sestak I, Baum M, et al. Effect of anastrozole and tamoxifen as adjuvant treatment for early-stage breast cancer: 10-year analysis of the ATAC trial. Lancet Oncol. 2010;11:1135-41. [PubMed: 21087898]

7. Regan MM, Neven P, Giobbie-Hurder A, et al. Evaluating letrozole and tamoxifen alone and in sequence for postmenopausal women with steroid hormone receptor-positive breast cancer: the BIG 1-98 randomized clinical trial at 8.1 years median follow-up. Lancet Oncol. 2011;12:1101-8. [PubMed: 22018631]

8. Keating NL, Landrum MB, Guadagnoli E, Winer EP, Ayanian JZ. Factors related to underuse of surveillance mammography among breast cancer survivors. J Clin Oncol. 2006;24:85-94. [PubMed: 16382117]

9. Keating NL, Landrum MB, Guadagnoli E, Winer EP, Ayanian JZ. Surveillance testing among survivors of early-stage breast cancer. J Clin Oncol. 2007;25:1074-81. [PubMed: 17369571]

10. Field TS, Doubeni C, Fox MP, et al. Under-utilization of surveillance mammography among older breast cancer survivors. J Gen Intern Med. 2008;23:158-63. [PubMed: 18060463]

11. Lash TL, Fox MP, Buist DSM, et al. Mammography surveillance and mortality in older breast cancer survivors. J Clin Oncol. 2007;25:3001-6. [PubMed: 17548838]

12. Buist DSM, Bosco JLF, Silliman RA, et al. Long-term surveillance mammography and mortality in older women with a history of early-stage invasive breast cancer. Breast Cancer Res Treat. 2013 10.1007/s10549-013-2720-x.

13. Bilimoria KY, Stewart AK, Winchester DP, Ko CY. The National cancer data base: a powerful initiative to improve cancer care in the United States. Ann Surg Oncol. 2008;15:683-90. [PubMed: 18183467]

14. Commission on cancer. Facility oncology registry data standards. Retrieved 4 May 2016 at https:// www.facs.org/*/media/files/quality programs/cancer/ncdb/fords2016.ashx.

15. Nurgalieva ZZ, Franzini L, Morgan R, Vernon SW, Liu CC, Du XL. Surveillance mammography use after treatment of primary breast cancer and racial disparities in survival. Med Oncol. 2013;30:691. [PubMed: 23975632]

16. Lash TL, Silliman RA. Medical surveillance after breast cancer diagnosis. Med Care. 2001;39:945-55. [PubMed: 11502952]

17. Schootman M, Jeffe DB, Lian M, Aft R, Gillanders WE. Surveillance mammography and the risk of death among elderly breast cancer patients. Breast Cancer Res Treat. 2008;111:489-96. [PubMed: 17957465]

18. Houssami N, Ciatto S, Martinelli F, Bonardi R, Duffy SW. Early detection of second breast cancers improves prognosis in breast cancer survivors. Ann Oncol. 2009;20:1505-10. [PubMed: 19297316]

19. Neuman HB, Schumacher JR, Francescatti AB, et al. Utility of clinical breast exams in detecting local-regional breast events after breast conservation in women with a personal history of high-risk breast cancer. Ann Surg Oncol. 2016;23:3385-91. [PubMed: 27491784] 
20. Parmar AD, Sheffield KM, Vargas GM, Han Y, Chao C, Riall TS. Quality of post-treatment surveillance of early-stage breast cancer in Texas. Surgery. 2013;154:214-25. [PubMed: 23889950]

21. Schapira MM, McAuliffe TL, Nattinger AB. Underutilization of mammography in older breast cancer survivors. Med Care. 2000;38:281-9. [PubMed: 10718353]

22. Keating NL, Landrum MB, Meara E, Ganz PA, Guadagnoli E. Do increases in the market share of managed care influence quality of cancer care in the fee-for-service sector? JNCI J Natl Cancer Institute. 2005;97:257-64.

23. Legg JS, Fauber TL, Ozcan YA. The influence of previous breast cancer upon mammography utilization. Women's Health Issues. 2003;13:62-7. [PubMed: 12732442]

24. Sabatino SA, Thompson TD, Richardson LC, Miller J. Health insurance and other factors associated with mammography surveillance among breast cancer survivors: results from a national survey. Med Care. 2012;50:270-6. [PubMed: 22193416]

25. Snyder CF, Frick KD, Peairs KS, et al. Comparing care for breast cancer survivors to non-cancer controls: a five-year longitudinal study. J Gen Intern Med. 2009;24:469-74. 26.

26. Thewes B, Lebel S, Seguin Leclair C, Butow P. A qualitative exploration of fear of cancer recurrence (FCR) amongst Australian and Canadian breast cancer survivors. Support Care Cancer 2016;24:2269-76. [PubMed: 26581900]

27. Buist DSM, Abraham LA, Barlow WE, et al. Diagnosis of second breast cancer events after initial diagnosis of early-stage breast cancer. Breast Cancer Res Treat. 2010;124:863-73. [PubMed: $20700648]$

28. Axelrod D, Smith J, Kornreich D, et al. Breast cancer in young women. J Am Coll Surg. 2008;206:1193-203. [PubMed: 18501818]

29. Bollet MA, Sigal-Zafrani B, Mazeau V, et al. Age remains the first prognostic factor for locoregional breast cancer recurrence in young ( $<40$ years) women treated with breast-conserving surgery first. Radiother Oncol. 2007;82:272-80. [PubMed: 17287037]

30. Anders CK, Hsu DS, Broadwater G, et al. Young age at diagnosis correlates with worse prognosis and defines a subset of breastcancers with shared patterns of gene expression. J Clin Oncol. 2008;26:3324-30. [PubMed: 18612148]

31. Wirtz HS, Boudreau DM, Gralow JR, et al. Factors associated with long-term adherence to annual surveillance mammography among breast cancer survivors. Breast Cancer Res Treat. 2014;143:541-50. [PubMed: 24407530]

32. Doubeni CA, Field TS, Ulcickas Yood M, et al. Patterns and predictors of mammography utilization among breast cancer survivors. Cancer. 2006;106:2482-8. [PubMed: 16634097]

33. Etim AE-EP, Schellhase KG, Sparapani R, Nattinger AB. Effect of model of care delivery on mammography use among elderly breast cancer survivors. Breast Cancer Res Treat. 2006;96:2939. [PubMed: 16538537]

34. Duffy CM, Clark MA, Allsworth JE. Health maintenance and screening in breast cancer survivors in the United States. Cancer Detect Prevent. 2006;30:52-7. [PubMed: 16455209]

35. Saslow D, Boetes C, Burke W, et al. American cancer society guidelines for breast screening with MRI as an adjunct to mammography. CA Cancer J Clin. 2007;57:75-89. [PubMed: 17392385]

36. Panageas KS, Sima CS, Liberman L, Schrag D. Use of hightechnology imaging for surveillance of early-stage breast cancer. Breast Cancer Res Treat. 2012;131:663-70. [PubMed: 21947679]

37. Orel S Who should have breast magnetic resonance imaging evaluation? J Clin Oncol. 2008;26:703-11. [PubMed: 18258977]

38. Mameri CS, Kemp C, Goldman SM, Sobral LA, Ajzen S. Impact of breast MRI on surgical treatment, axillary approach, and systemic therapy for breast cancer. Breast J. 2008;14:236-44 [PubMed: 18476882]

39. DeMartini W, Lehman C, Partridge S. Breast MRI for Cancer detection and characterization: a review of evidence-based clinical applications. Acad Radiol. 2008;15:408-16. [PubMed: 18342764]

40. Morris EA, Liberman L, Ballon DJ, et al. MRI of occult breast carcinoma in a high-risk population. AJR Am J Roentgenol. 2003;181:619-26. [PubMed: 12933450] 
41. Hillman BJ, Goldsmith JC. The uncritical use of high-tech medical imaging. N Engl J Med. 2010;363:4-6. [PubMed: 20573920]

42. Brennan S, Liberman L, Dershaw DD, Morris E. Breast MRI screening of women with a personal history of breast cancer. AJR Am J Roentgenol. 2010;195:510-6. [PubMed: 20651211]

43. Gorechlad JW, McCabe EB, Higgins JH, et al. Screening for recurrences in patients treated with breast-conserving surgery: is there a role for MRI? Ann Surg Oncol. 2008;15:1703-9. [PubMed: 18266039] 


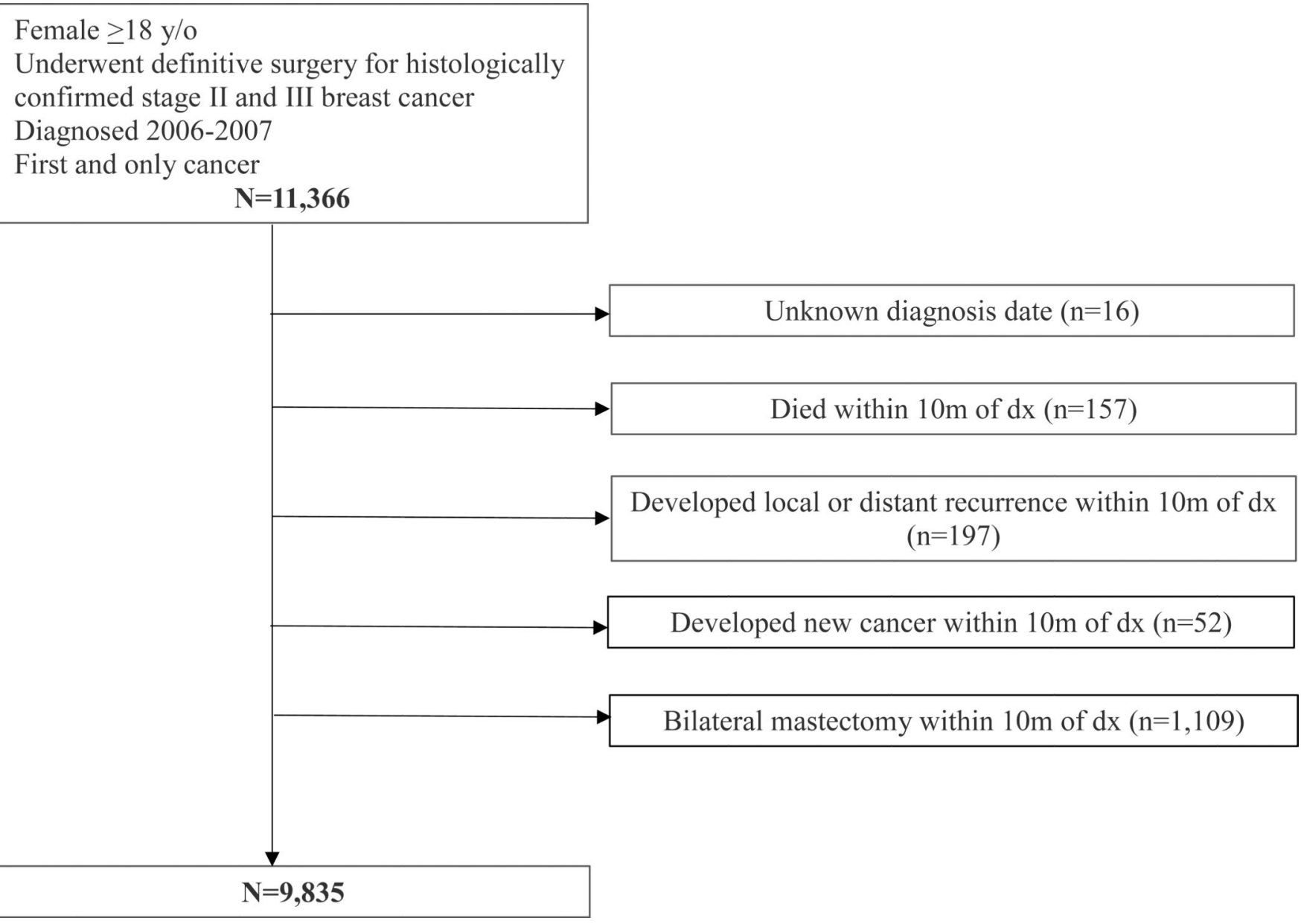

Figure 1:

Patient selection 
100

90

80

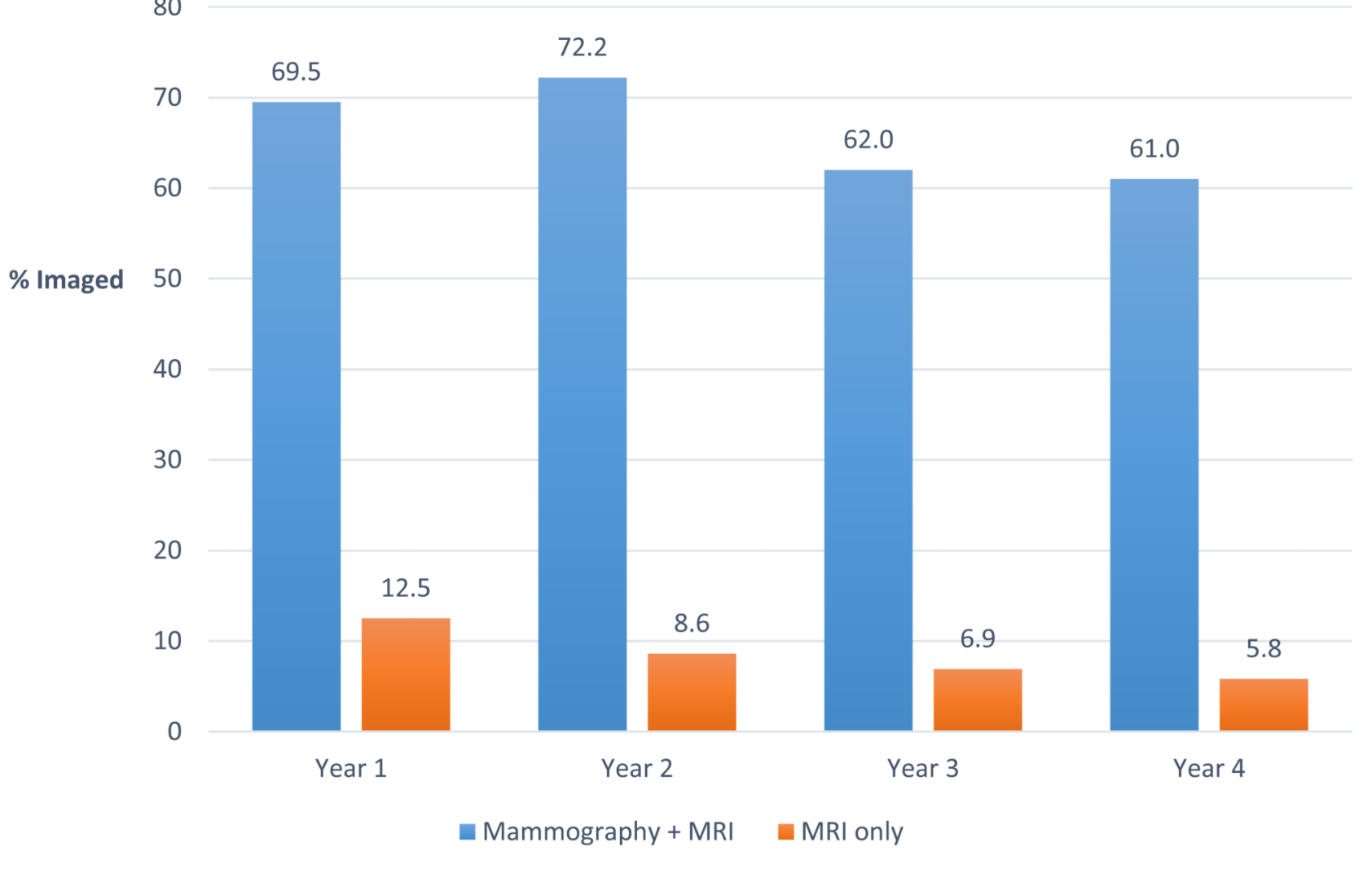

Figure 2:

Annual receipt of surveillance imaging after treatment for stage 2 and 3 breast cancer $(\mathrm{n}=9622)^{*}$

*Patients were censored for local or distant recurrence, new primary cancer, death or last contact, bilateral mastectomy 
Table 1:

Characteristics of women with stage 2 or 3 breast cancer at diagnosis by receipt of post-treatment breast imaging.

\begin{tabular}{|c|c|c|c|c|c|c|}
\hline & $\begin{array}{c}\text { Total } \\
(\mathbf{n}=\mathbf{9 , 6 2 2})\end{array}$ & $\begin{array}{c}\text { Post-treatment } \\
\text { imaging received }\end{array}$ & $P$ value & $\underset{(\mathbf{n}=7,457)}{\text { Total }}$ & $\begin{array}{c}\text { Post-treatment } \\
\text { imaging received }\end{array}$ & $P$ value \\
\hline & & Year 1 & & & Years 1-4 & \\
\hline & n $(\%)$ & $\begin{array}{l}\text { n (\% of elligible } \\
\text { patients })\end{array}$ & & n $(\%)$ & $\begin{array}{l}\text { n (\% of elligible } \\
\text { patients })\end{array}$ & \\
\hline Age (years) & & & $<.0001$ & & & $<.0001$ \\
\hline$<50$ & $2488(25.9)$ & $1725(69.3)$ & & $1962(26.3)$ & $779(39.7)$ & \\
\hline $50-59$ & $2458(25.5)$ & $1794(73)$ & & $1979(26.5)$ & $874(44.2)$ & \\
\hline $60-69$ & $2138(22.2)$ & $1571(73.5)$ & & $1738(23.3)$ & $833(47.9)$ & \\
\hline $70-79$ & $1572(16.3)$ & $1082(68.8)$ & & $1193(16)$ & $526(44.1)$ & \\
\hline 280 & $966(10)$ & $511(52.9)$ & & $585(7.8)$ & $146(25)$ & \\
\hline Race & & & $<.0001$ & & & 0.0002 \\
\hline White & $8002(83.2)$ & $5678(71)$ & & $6280(84.2)$ & $2722(43.3)$ & \\
\hline Black & $1189(12.3)$ & $734(61.7)$ & & $832(11.2)$ & $292(35.1)$ & \\
\hline Other/unknown & $431(4.5)$ & $271(62.9)$ & & $345(4.6)$ & $144(41.7)$ & \\
\hline $\begin{array}{l}\text { Education (\% in zipcode with no High } \\
\text { school degree) }\end{array}$ & & & $<.0001$ & & & $<.0001$ \\
\hline $29 \%$ or more & $1553(16.8)$ & $992(63.9)$ & & $1165(16.2)$ & $415(35.6)$ & \\
\hline $20 \%-28.9 \%$ & $2160(23.3)$ & $1471(68.1)$ & & $1622(22.5)$ & $653(40.3)$ & \\
\hline $14 \%-19.9 \%$ & $2397(25.9)$ & $1709(71.3)$ & & $1922(26.7)$ & $836(43.5)$ & \\
\hline$<14 \%$ & $3150(34)$ & $2274(72.2)$ & & $2492(34.6)$ & $1169(46.9)$ & \\
\hline Insurance & & & $<.0001$ & & & $<.0001$ \\
\hline Uninsured/unknown & $429(4.5)$ & $278(64.8)$ & & $314(4.2)$ & $95(30.3)$ & \\
\hline Private & $5035(52.3)$ & $3700(73.5)$ & & $4123(55.3)$ & 1879 (45.6) & \\
\hline Medicaid & $737(7.7)$ & $484(65.7)$ & & $519(7)$ & $182(35.1)$ & \\
\hline Medicare/other government & $3421(35.6)$ & $2221(64.9)$ & & $2501(33.5)$ & $1002(40.1)$ & \\
\hline Comorbidity & & & $<.0001$ & & & $<.0001$ \\
\hline None & $5779(60.1)$ & $4181(72.3)$ & & $4684(62.8)$ & $2098(44.8)$ & \\
\hline One & 2467 (25.6) & $1638(66.4)$ & & $1878(25.2)$ & $747(39.8)$ & \\
\hline Two or more & $1376(14.3)$ & $864(62.8)$ & & $895(12)$ & $313(35)$ & \\
\hline Tumor size $(\mathbf{c m})^{*}$ & & & $<.0001$ & & & $<.0001$ \\
\hline$<2$ & $2802(29.1)$ & $2091(74.6)$ & & $2375(31.8)$ & $1104(46.5)$ & \\
\hline $2-5$ & $5648(58.7)$ & $3857(68.3)$ & & $4362(58.5)$ & $1799(41.2)$ & \\
\hline$>5$ & $1015(10.5)$ & $632(62.3)$ & & $615(8.2)$ & $221(35.9)$ & \\
\hline Nodal status ${ }^{*}$ & & & 0.434 & & & 0.040 \\
\hline Negative & $3145(32.7)$ & $2223(70.7)$ & & $2556(34.3)$ & $1051(41.1)$ & \\
\hline Positive & $6206(64.5)$ & $4338(69.9)$ & & $4735(63.5)$ & $2065(43.6)$ & \\
\hline
\end{tabular}

Ann Surg Oncol. Author manuscript; available in PMC 2019 December 21. 


\begin{tabular}{|c|c|c|c|c|c|c|}
\hline & $\begin{array}{c}\text { Total } \\
(\mathbf{n}=\mathbf{9 , 6 2 2})\end{array}$ & $\begin{array}{l}\text { Post-treatment } \\
\text { imaging received }\end{array}$ & $P$ value & $\begin{array}{c}\text { Total } \\
(\mathbf{n}=\mathbf{7 , 4 5 7})\end{array}$ & $\begin{array}{l}\text { Post-treatment } \\
\text { imaging received }\end{array}$ & $P$ value \\
\hline & & Year 1 & & & Years 1-4 & \\
\hline & n $(\%)$ & $\begin{array}{c}\text { n (\% of elligible } \\
\text { patients) }\end{array}$ & & n $(\%)$ & $\begin{array}{c}\text { n (\% of elligible } \\
\text { patients) }\end{array}$ & \\
\hline ER/PR status ${ }^{*}$ & & & $<.0001$ & & & $<.0001$ \\
\hline ER and PR negative & $2243(23.4)$ & $1507(67.2)$ & & $1516(20.4)$ & $633(41.8)$ & \\
\hline ER or PR positive & $7236(75.4)$ & $5117(70.7)$ & & $5842(78.5)$ & $2506(42.9)$ & \\
\hline Borderline/Unknown & $113(1.2)$ & $43(38.1)$ & & $81(1.1)$ & $13(16)$ & \\
\hline Her2_neu & & & $<.0001$ & & & $<.0001$ \\
\hline Negative & 7095 (73.7) & $5050(71.2)$ & & $5532(74.2)$ & $2410(43.6)$ & \\
\hline Positive & $1833(19.1)$ & $1271(69.3)$ & & 1417 (19) & $617(43.5)$ & \\
\hline Borderline/Unknown & $694(7.2)$ & $362(52.2)$ & & $508(6.8)$ & $131(25.8)$ & \\
\hline Locoregional therapy ${ }^{*}$ & & & $<.0001$ & & & $<.0001$ \\
\hline $\mathrm{BCS} / \mathrm{RT}$ & $4230(43.9)$ & $3343(79)$ & & $3573(47.9)$ & $1789(50.1)$ & \\
\hline BCS alone & $479(4.9)$ & $219(45.7)$ & & $319(4.3)$ & $84(26.3)$ & \\
\hline Mastectomy/RT & $2189(22.7)$ & $1517(69.3)$ & & $1558(20.9)$ & $619(39.7)$ & \\
\hline Mastectomy alone & $2508(26.1)$ & $1553(61.9)$ & & $1855(25.9)$ & $649(35)$ & \\
\hline Chemotherapy ${ }^{*}$ & & & $<.0001$ & & & $<.0001$ \\
\hline No & $2546(26.4)$ & $1582(62.1)$ & & $1830(24.5)$ & $692(37.8)$ & \\
\hline Yes & $6912(71.8)$ & $5067(73.3)$ & & $5515(73.9)$ & $2460(44.6)$ & \\
\hline Facility Type * & & & 0.009 & & & 0.058 \\
\hline Community & $2810(29.2)$ & $1888(67.2)$ & & $2144(28.8)$ & $868(40.5)$ & \\
\hline Comprehensive community/other & $5074(52.7)$ & $3568(70.3)$ & & $3957(53.1)$ & $1691(42.7)$ & \\
\hline Teaching/Research & $1684(17.5)$ & $1189(70.6)$ & & $1310(17.6)$ & $575(43.9)$ & \\
\hline Location & & & 0.865 & & & 0.294 \\
\hline Rural & $219(2.4)$ & $151(68.9)$ & & $176(2.5)$ & $68(38.6)$ & \\
\hline Urban & $8973(97.6)$ & $6235(69.5)$ & & $6961(97.5)$ & 2965 (42.6) & \\
\hline MRI 12 months before diagnosis & & & $<.0001$ & & & $<.0001$ \\
\hline No & $1763(18.3)$ & $1405(79.7)$ & & $1443(19.4)$ & $767(53.2)$ & \\
\hline Yes & $6770(70.4)$ & $4795(70.8)$ & & $5206(69.8)$ & $2218(42.6)$ & \\
\hline Unknown & $1089(11.3)$ & $483(44.4)$ & & $808(10.8)$ & $173(21.4)$ & \\
\hline
\end{tabular}

* numbers do not add up to total due to missing values

Abbreviations: $E R$ estrogen receptor positive, $P R$ progesterone receptor positive, $B C S$ breast conserving surgery, $R T$ radiation therapy, $M R I$ magnetic resonance imaging 
Table 2:

Adjusted odds ratio (OR) of breast imaging received after treatment by women with a diagnosis of stage 2 or 3 breast cancer *

\begin{tabular}{|c|c|c|c|}
\hline Variables & $\begin{array}{l}\text { Adjusted } \\
\text { OR }\end{array}$ & $(95 \% \mathrm{CI})$ & $P$ value \\
\hline \multicolumn{4}{|l|}{ Age (years) } \\
\hline$<50$ & 1 & & \\
\hline $50-59$ & 1.20 & $1.08-1.33$ & $<.0001$ \\
\hline $60-69$ & 1.48 & $1.32-1.67$ & $<.0001$ \\
\hline $70-79$ & 1.53 & $1.3-1.79$ & $<.0001$ \\
\hline 280 & 0.86 & $0.71-1.03$ & 0.107 \\
\hline \multicolumn{4}{|l|}{ Race } \\
\hline White & 1 & & \\
\hline Black & 0.78 & $0.69-0.87$ & $<.0001$ \\
\hline Other/unknown & 0.84 & $0.71-1$ & 0.053 \\
\hline \multicolumn{4}{|c|}{ Education (\% in zipcode with no High school degree) ${ }^{*}$} \\
\hline $29 \%$ or more & 1 & & \\
\hline $20 \%-28.9 \%$ & 1.12 & $0.99-1.26$ & 0.069 \\
\hline $14 \%-19.9 \%$ & 1.20 & $1.07-1.35$ & 0.003 \\
\hline$<14 \%$ & 1.17 & $1.04-1.31$ & 0.008 \\
\hline \multicolumn{4}{|l|}{ Insurance } \\
\hline Uninsured/unknown & 0.80 & $0.65-0.93$ & 0.006 \\
\hline Private & 1 & & \\
\hline Medicaid & 0.81 & $0.70-0.93$ & 0.004 \\
\hline Medicare/other government & 0.84 & $0.75-0.94$ & 0.008 \\
\hline \multicolumn{4}{|l|}{ Location } \\
\hline Rural & 1 & & \\
\hline Urban & 0.98 & $0.77-1.24$ & 0.845 \\
\hline \multicolumn{4}{|l|}{ Comorbidity } \\
\hline None & 1 & & \\
\hline One & 0.88 & $0.81-0.96$ & 0.003 \\
\hline Two or more & 0.79 & $0.71-0.88$ & $<0.0001$ \\
\hline \multicolumn{4}{|l|}{ Tumor size (cm) } \\
\hline$<2$ & 1 & & \\
\hline $2-5$ & 0.86 & $0.79-0.94$ & 0.002 \\
\hline$>5$ & 0.74 & $0.64-0.86$ & $<.0001$ \\
\hline \multicolumn{4}{|l|}{ Nodal status } \\
\hline Negative & 1 & & \\
\hline Positive & 0.87 & $0.77-0.98$ & 0.002 \\
\hline ER/PR status & & & \\
\hline
\end{tabular}

Ann Surg Oncol. Author manuscript; available in PMC 2019 December 21. 


\begin{tabular}{|l|c|c|c|}
\hline Variables & $\begin{array}{c}\text { Adjusted } \\
\text { OR }\end{array}$ & $\mathbf{( 9 5 \%}$ CI) & P value \\
\hline ER and PR negative & 1 & & \\
\hline ER or PR positive & 1.13 & $1.03-1.24$ & $\mathbf{0 . 0 1}$ \\
\hline Borderline/Unknown & 0.47 & $0.3-0.73$ & $\mathbf{0 . 0 0 1}$ \\
\hline Her2_neu & & & \\
\hline Negative & 1 & & \\
\hline Positive & 1.03 & $0.91-1.1$ & 0.968 \\
\hline Borderline/Unknown & 0.58 & $0.5-0.68$ & $<.0001$ \\
\hline Locoregional therapy & & & \\
\hline BCS/RT & 1 & & \\
\hline BCS alone & 0.36 & $0.3-0.43$ & $<.0001$ \\
\hline Mastectomy/RT & 0.70 & $0.63-0.78$ & $<.0001$ \\
\hline Mastectomy alone & 0.57 & $0.52-0.63$ & $<.0001$ \\
\hline Chemotherapy & & & \\
\hline No & 1 & & \\
\hline Yes & 1.34 & $1.20-1.49$ & $<.0001$ \\
\hline Facility Type & & & \\
\hline Community & 1.06 & $0.97-1.16$ & 0.177 \\
\hline Comprehensive community/other & & $1.25-1.54$ & $<.0001$ \\
\hline Teaching/Research & $0.98-1.24$ & 0.096 \\
\hline Location & & & \\
\hline Rural & & & \\
\hline Urban & & & \\
\hline MRI 12 months before diagnosis & & & \\
\hline No & & & \\
\hline Yes & & & \\
\hline Unknown & & & \\
\hline
\end{tabular}

Multivariable repeated-measures logistic regression with generalized estimating equations (GEE)

Abbreviations: $E R$ estrogen receptor positive, $P R$ progesterone receptor positive, $B C S$ breast conserving surgery, $R T$ radiation therapy, $M R I$ magnetic resonance imaging 